\title{
Air accumulation in high-lift siphon hoses under the influence of air dissolution and diffusion
}

\author{
Yue-liang $\mathrm{CAI}^{1}$, Hong-yue SUN ${ }^{\dagger+2}$, Yue-quan $\mathrm{SHANG}^{1}$, Zhi-jun $\mathrm{WU}^{1}$ \\ $\left({ }^{1}\right.$ College of Civil Engineering and Architecture, Zhejiang University, Hangzhou 310058, China) \\ $\left({ }^{2}\right.$ Ocean College, Zhejiang University, Hangzhou 310058, China) \\ †E-mail: shy@zju.edu.cn
}

Received Dec. 13, 2014; Revision accepted June 8, 2015; Crosschecked Aug. 22, 2015

\begin{abstract}
In this study, air accumulation at the top of a long-term-high-lift motionless siphon hose due to air dissolution and diffusion is studied. Many factors can induce air accumulation in siphon hoses during dry seasons. In this study, effects of the unavoidable factors, such as air diffusion and dissolved-air release, are investigated. Based on experimental observations and theoretical analysis, the following results are obtained: (1) pressure decrease in high-lift siphon hoses will cause release of supersaturated air and induce a maximum $1.5 \mathrm{~m}$ long air column at the top of the siphon hose; (2) temperature increase will cause a maximum $0.55 \mathrm{~m}$ long air column; (3) air diffusion from water will lead to a less than $0.01 \mathrm{~mm}$ increment of the air column per day, which is considered to be negligible compared with that induced by air release due to pressure and temperature variations. Results indicate that high-lift siphon drainage can also be effectively used in arid districts. During siphon drainage design, at least $2.05 \mathrm{~m}$ long space to the safety level should be left for underground water rise, or the outlet should be kept $4.1 \mathrm{~m}$ lower than the inlet to guarantee that the released air will be gathered in the descending hoses.
\end{abstract}

Key words: Slope, Siphon drainage, Motionless flow during dry season, Air accumulation, Air diffusion, Temperature doi: $10.1631 /$ jzus.A1400358

\section{Introduction}

Siphon drainage is an automatic system controlled by the underground water level. Therefore, it can be regarded as a timely discharge method and has been successfully utilized in slope drainage for its capability in discharging deep groundwater so as to control the groundwater within a safety level (Gress, 1988; 1991; Zhang and Zhang, 1999; Mrvik and Bomont, 2012). Since slope drainage is a long-term process, it is necessary to make sure the siphon

\footnotetext{
ॠ Corresponding author

" Project supported by the National "Twelfth Five-Year" Plan for Science \& Technology Support Program of China (No. 2012BAK10B06), and the Zhejiang Provincial Department of Education Funded Projects (No. Z201122174), China

(DiD ORCID: Yue-liang CAI, http://orcid.org/0000-0001-9293-1934; Hong-yue SUN, http://orcid.org/0000-0002-2267-305X

(C) Zhejiang University and Springer-Verlag Berlin Heidelberg 2015
}

system is long-lasting. Once interrupted, the siphon system is difficult to recover because of traffic restrictions (Chen et al., 2006; Yang et al., 2009). Thus, a comprehensive analysis to deal with problems which may induce the collapse of a slope siphon should be conducted for long-term drainage systems. To initialize the siphon flow, the following two basic conditions should be satisfied. First, the potential energy at the inlet of a siphon hose must be larger than that at the outlet (Ramette and Ramette, 2011). Second, the difference between the static pressure at the inlet and the negative pressure at the top of a siphon hose must exceed the water column height in the ascending hose (Gress, 2008; Hughes and Gurung, 2014). The above two studies demonstrated that keeping a negative pressure at the top of a siphon hose is the basis for ensuring a long-term effective siphon system. Most siphon systems, such as siphon rain gauge, flush toilet, roof rainwater siphon, and 
reservoir siphon drainage (Lu et al., 2005; Hager, 2010; Campbell, 2014), can naturally satisfy that negative pressure condition regardless of air accumulation. However, slope siphon drainage is different. It has the following two special characteristics: (1) deep groundwater requires a high-lift siphon; and (2) a long dry season results in a long period of motionless flow. Therefore, it is necessary to investigate the effect of these two factors on the effectiveness of long-lasting slope siphon drains.

\section{Air accumulation in long-term motionless siphon hoses}

Deep slope groundwater drainage requires a high-lift siphon, which makes the top area of the siphon hoses a near-vacuum (Cai et al., 2014). The negative pressure condition in this area determines whether the siphon system (Fig. 1) can self-restart at the next rainy season. Air accumulation in siphon hoses during dry seasons can be influenced by many factors. Most of them can be solved during engineering. However, some of them are inevitable, such as air diffusion from inlet hose to the top and dissolved-air release induced by pressure decrease and temperature increase. Therefore, it is necessary to evaluate the effect of these inevitable factors on the effectiveness of siphons in long-lasting slope drainage, especially for cases experiencing a lengthy dry season.

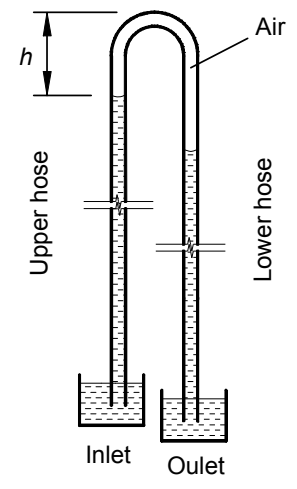

Fig. 1 Schematic diagram of siphon system

Air is water-soluble, with solubility closely related to pressure and temperature. The solution can be regarded as ideal one (Frank and Evans, 1945). At a fixed temperature, the solubility of gas dissolved in liquid follows Henry's law:

$$
P_{B}=k_{X} X_{B},
$$

where $k_{X}$ is Henry's constant; $P_{B}$ is the partial pressure; and $X_{B}$ is the molar fraction of the gas in the liquid. As shown in Eq. (1), the solubility of a gas in a liquid is proportional to the equilibrium pressure at the liquid surface. In high-lift siphon hoses, pressure decreases gradually with increased elevation (Fig. 2). Therefore, dissolved air will be released during siphon flow due to the pressure decrease. As a result, bubbles of air will accumulate (Sun et al., 2014). Since a high-lift siphon has a high pressure variation, an intensive air release will result. As low pressure corresponds to a large molar volume, a small amount of released air can occupy a large space. This is the fundamental difference between low- and high-lift siphons.

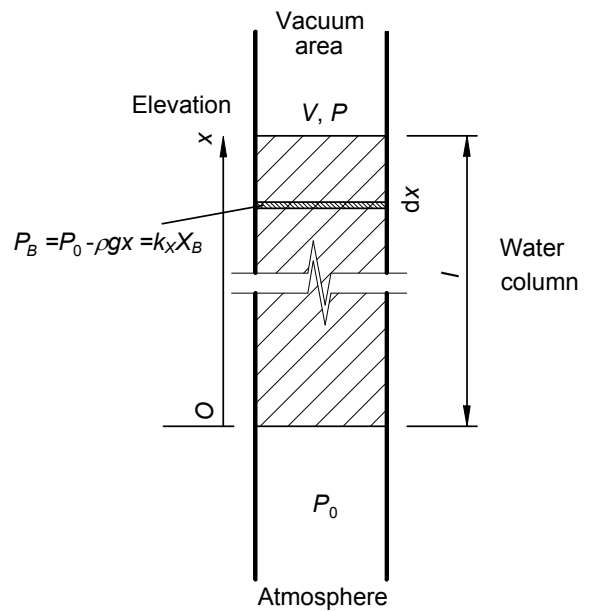

Fig. 2 Simplified physical model diagram $V$ and $P$ are the volume and pressure of the vacuum area, respectively; the other symbols and formula will be explained in Section 3.3

Gress (1991) first noticed air accumulation in high-lift siphon drainage. Cai et al. (2014) showed that in small diameter siphon hoses (e.g., diameter $d<4.0 \mathrm{~mm}$ ) the bubbles can occupy the entire section of the siphon hoses (Fig. 3b) and make the siphon flow stop. Meanwhile, for hoses with a larger diameter (e.g., $d>10 \mathrm{~mm}$ ), the bubbles stagnating at the highest point of the siphon hose cannot occupy the whole cross-section because of the limitation of surface tension. Thus, there will still be a water channel beneath the bubble (Fig. 3a). However, bubbles cannot be discharged with the water flow, and they are likely to accumulate and eventually make the outflow 
stop. For both these two cases, to resume the outflow, the bubbles need to be ejected by strong hydrostatic pressure treatment in borehole.

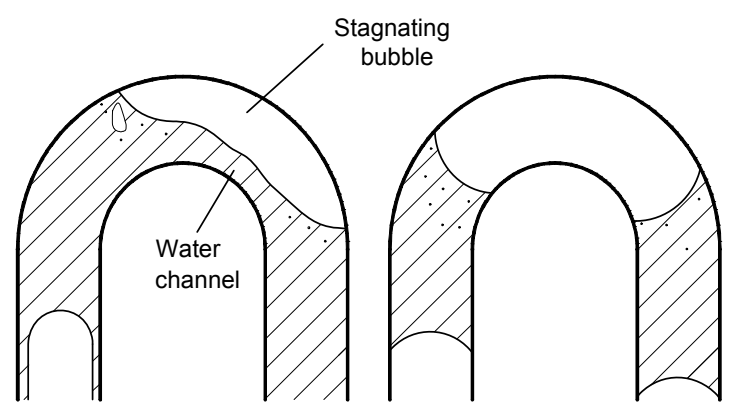

(a)

(b)

Fig. 3 Different flow patterns at the top of large (a) and small (b) diameter hoses

With smaller than $4.0 \mathrm{~mm}$ siphon hoses, integral slug flow can ensure bubbles are discharged with water in continuous siphon drainage, even under very low flow velocity (Cai et al., 2014; Sun et al., 2014). However, irregular rainfall may result in long-term dry seasons and motionless siphon flow. Since the static water in siphon hoses can no longer discharge air out of the hoses, the excessive air will be released and accumulate in an air column at the top of the siphon hoses. Such a phenomenon is also observed in our laboratory tests as shown in Fig. 1. When the air column length $h$ at the ascending hose is large, a high water level rise at the inlet is needed to restart the siphon. The hydrostatic pressure required to eject the bubble sometimes may be unacceptable or at least undesirably high. As a result, a landslide may happen due to significant groundwater level rise, which still, however, is not enough to restart the siphon drainage system.

Though the top of the siphon hose is at a nearly vacuum status, the inlet and outlet of the siphon hose are at a natural condition, so air solubility varies throughout the whole siphon hose. As a result, an air solubility gradient forms from the inlet and outlet to the top of the siphon hose, inducing air diffusion from the inlet and outlet to the top. Such air diffusion inevitably increases air accumulation in the vacuum area, which will enlarge the air column length $h$ at the top of the siphon hose. Therefore, air accumulation induced by air dissolution and diffusion should be seriously investigated during the application of siphon drainage.

\section{Theoretical study of air dissolution and diffusion in siphon hoses}

Oxygen and nitrogen have different solubilities and diffusion coefficients in water. During air diffusion, the proportion of the oxygen and nitrogen in the dissolved air will change and the partial pressure of each gas will also change. Therefore, because of its mixed components it is challenging to consider the overall dissolution and diffusion of air. Since the solubility and diffusion coefficients of the two main gases in air have the same order of magnitude, it is reasonable to simplify air as a single gas for engineering considerations.

\subsection{Air diffusion from chemical potential calculation}

The solubility of air in water is very low (Benson and Krause, 1984). Therefore, a solution of air and water obeys Raoult's law and Henry's law (Frank and Evans, 1945). The chemical potential of solute $B$ can thus be written as (Radke and Prausnitz, 1972; Jacobson, 1995)

$$
\mu_{B}=\mu_{B}^{\theta}+R T \ln X_{B}+\int_{P^{\theta}}^{P} V_{B, \mathrm{~m}} \mathrm{~d} P
$$

where $\mu_{B}$ is the chemical potential of solute $B$ (air); the constant value $\mu_{B}^{\theta}$ is the chemical potential of pure air under normal temperature-pressure (NTP); the superscript $\theta$ indicates the concluded values are under standard state; $R$ is the ideal gas constant $(8.314 \mathrm{~J} /(\mathrm{K} \cdot \mathrm{mol})) ; T$ is the ambient temperature; $X_{B}$ is the molar fraction of air in water, which equals the air solubility in cases where air in siphon hose is saturated everywhere; and $V_{B, \mathrm{~m}}$ is the partial molar volume of air in dilute solution.

Since slight dissolution of air in water has little effect on solution volume, $V_{B, \mathrm{~m}}$ can be treated as a constant value. In a high-lift siphon, since the solubility of air in water obeys Henry's law (Eq. (1)) and the equilibrium partial pressure of air $P_{B}$ at a certain elevation can be regarded as the barometric pressure $P$, the chemical potential expression shown in Eq. (2) can then be rewritten as

$$
\mu_{B}=\mu_{B}^{\theta}+R T \ln \frac{P}{k_{X}}+V_{B, \mathrm{~m}}\left(P-P^{\theta}\right)
$$


According to Eq. (3), the chemical potential of air in siphon hoses decreases with decrease in the barometric pressure $P$. Therefore, the chemical potential of air in siphon hoses decreases as the elevation increases since the air pressure $P$ decreases with the elevation increase in siphon hoses. As a result, air spontaneously diffuses from the bottom to the top of siphon hoses.

\subsection{Original air release in siphon hoses}

Immediately after the siphon flow stops, the dissolved air in the water is assumed to be equally distributed in the entire siphon hose, and equals the solubility of air under standard atmosphere. Due to pressure change after a long resting time, the air solubility at different elevations decreases rapidly with height. Therefore, the amount of air in water can exceed its actual solubility, resulting in air release. The released air then moves to the top of the siphon hose and accumulates as a long air column (Fig. 1). This phenomenon was firstly observed in slow siphon flows by Sun et al. (2014). Under low air pressure conditions, a small amount of air occupies a very large space and induces a long air column. Therefore, the release of dissolved air should be treated as the basis for air accumulation in siphon hoses.

Ignoring the mass of air in water, the molar fraction $X_{B}$ can be transferred into mass fraction $w_{B}$ as:

$$
w_{B}=\frac{M_{B}}{M_{A}} X_{B},
$$

where $M_{A}$ and $M_{B}$ denote the molar mass of solvent water and solute air, respectively.

According to Henry's law, by simplifying the siphon hoses as a 1D model (Fig. 2), the amount of air released from an infinitesimal length of water column $\mathrm{d} x$ can be expressed as

$$
\begin{gathered}
\mathrm{d} n_{B}=\left(\frac{P_{0}}{k_{X}}-\frac{P_{0}-\rho g x}{k_{X}}\right) \frac{M_{B}}{M_{A}} \cdot \frac{\rho A}{M_{A}} \mathrm{~d} x=\frac{\rho^{2} g A M_{B}}{k_{X} M_{A}^{2}} x \mathrm{~d} x,(5) \\
n_{B}=\int_{0}^{l} \frac{\rho^{2} g A M_{B}}{k_{X} M_{A}^{2}} x \mathrm{~d} x=\frac{\rho^{2} g A l^{2} M_{B}}{2 k_{X} M_{A}^{2}}
\end{gathered}
$$

where $l$ denotes the length of the calculated water column, which is taken as $l \approx 10 \mathrm{~m}$ since the limit of siphon lift is around $10.24 \mathrm{~m}$ under NTR; $\rho$ is the water density; $A$ is the cross-sectional area of the water column, which is taken as $4 \mathrm{~mm}$ in the calculation; $P_{0}$ is the natural atmosphere pressure; and $g$ is the gravitational acceleration.

Henry's coefficient $k_{X}$ is temperature dependent. In this study, a general temperature ranging between $0{ }^{\circ} \mathrm{C}$ and $40{ }^{\circ} \mathrm{C}$ with corresponding $k_{X}$ ranging from $4.38 \mathrm{GPa}$ to $8.82 \mathrm{GPa}$ is considered. Substituting the $k_{X}$ values into Eq. (6), the amount of air released from a $10 \mathrm{~m}$-long siphon hose can be obtained. At $0{ }^{\circ} \mathrm{C}$, the released air is $n_{B} \approx 1.25 \times 10^{-4} \mathrm{~mol}$, while it is $n_{B} \approx$ $6.2 \times 10^{-5} \mathrm{~mol}$ at $40^{\circ} \mathrm{C}$.

The released air ultimately accumulates at the top of the siphon hoses. The length of the accumulated air column can be obtained by

$$
\Delta l=n_{B} V_{\mathrm{m}} / A,
$$

where $V_{\mathrm{m}}$ denotes the final molar volume, which can be written as

$$
V_{\mathrm{m}} \cdot\left(\rho g \cdot \frac{n_{B} V_{\mathrm{m}}}{A}+P_{\mathrm{w}}\right)=0.0224 \times P_{0},
$$

where $P_{\mathrm{w}}$ is the saturated vapor pressure of air (Sanjari, 2013). Since the molar volume decreases with increasing pressure, the decreasing molar volume can restrain air volume enlargement during its accumulation (Fekete et al., 2013).

According to Eq. (8), the molar volumes at $0{ }^{\circ} \mathrm{C}$ and $40{ }^{\circ} \mathrm{C}$ are both $V_{\mathrm{m}} \approx 0.15 \mathrm{~m}^{3} / \mathrm{mol}$. Therefore, the cumulative length of air originally released from a $10 \mathrm{~m}$-long siphon hose is about $\Delta l \approx 1.48 \mathrm{~m}$ at $0{ }^{\circ} \mathrm{C}$ while it is $\Delta l \approx 0.74 \mathrm{~m}$ at $40{ }^{\circ} \mathrm{C}$. Therefore, excess air released from water could eventually form an air column with a length of $0.74-1.48 \mathrm{~m}$, which has to be seriously considered in engineering practice.

An entire siphon system consists of an ascending hose and a descending hose as shown in Fig. 1. As observed during experiments, pressure is the same along the air column at the top of the siphon hose when the siphon is under flow conditions, which leads to the same length of water column at the ascending and descending hoses. Some time after the siphon flow stops, an air column of length of 0.74-1.48 m due to excess air release will form in both the ascending and descending hoses. These two columns 
will then combine into an $\cap$-column with a total length of about $1.48-2.96 \mathrm{~m}$ at the top of the siphon hose. If the inlet and outlet elevations of the siphon are equal, the $\cap$-column will be symmetrically distributed at the top of the siphon hose. However, if the inlet elevation is higher than the outlet one, the $\cap$-column will mainly be in the descending hose. Therefore, in a siphon drainage design, at least a $1.5 \mathrm{~m}$ length of column space to the safety level should be left to allow for underground water rise, or the outlet should be $3 \mathrm{~m}$ lower than the inlet to guarantee that the released air will be gathered in the descending hose.

\subsection{Air diffusion under a certain temperature}

As shown in Fig. 1, air will spontaneously diffuse from the bottom to the top of the siphon hose. Since air dissolution at the top of siphon hose is unavoidable, it is essential to investigate the effect of the spontaneous diffusion rate on the efficiency of a high elevation siphon.

In this study, the siphon hose is simplified to a 1D model as shown in Fig. 2. As illustrated in Fig. 2, the bottom part of the hose is under natural atmosphere pressure $P_{0}$ while the top part is under vacuum. The length of the water column retained in the siphon hose after the siphon flow stops is assumed to be $l$. Therefore, the pressure at the top vacuum area due to air release is

$$
P_{B}=P_{0}-\rho g l
$$

After the siphon flow stops, air is considered to be saturated in the siphon hose. Therefore, the concentration of air can be represented by its solubility as

$$
P_{B}=k_{X} X_{B}
$$

Therefore, the amount of air dissolved in water decreases linearly with the increase in elevation. When the concentration is very dilute, the concentration can be expressed by a molar fraction as

$$
c_{B}=\frac{P_{B} \rho}{k_{X} M_{A}} .
$$

Since the pressure at point $x$ is $P_{B}=P_{0}-\rho g x$, Eq. (9) can then be expressed as

$$
C=\frac{\left(P_{0}-\rho g x\right) \rho}{k_{X} M_{A}} .
$$

According to Fick's first law (Gao and Cui, 1983) and Eq. (10), the diffusion rate can be obtained:

$$
F=-D \frac{\partial C}{\partial x}=\frac{D \rho^{2} g}{k_{X} M_{A}},
$$

where $D$ is the air diffusion coefficient in water.

Both $D$ and $k_{X}$ are temperature dependent (Cussler, 1984; Xu et al., 2009). Table 1 shows the $D$ and $k_{X}$ values under different temperatures. The relation between the diffusion rate and the temperature is shown in Fig. 4. As illustrated in Fig. 4, the diffusion rate increases approximate linearly with increase in temperature. Taking the unfavorable temperature $40{ }^{\circ} \mathrm{C}$ for example, the diffusion rate is $F \approx 1.8 \times 10^{-10} \mathrm{~mol} /\left(\mathrm{m}^{2} \cdot \mathrm{s}\right)$. Therefore, the diffused air per day in a $4 \mathrm{~mm}$-in-diameter siphon hose at $40{ }^{\circ} \mathrm{C}$ is about

$$
n=F A t=2 \times 10^{-10} \mathrm{~mol},
$$

where the cross-sectional area $A$ of the siphon hose is $1.26 \times 10^{-5} \mathrm{~m}^{2}$ in this equation; and $t$ is the duration time (one day $=86400 \mathrm{~s}$ in this equation).

Table 1 Diffusion coefficient $D$ and Henry's coefficient $\boldsymbol{k}_{X}$ of air in water under different temperatures

\begin{tabular}{ccc}
\hline $\begin{array}{c}\text { Temperature } \\
\left({ }^{\circ} \mathrm{C}\right)\end{array}$ & $\begin{array}{c}\text { Diffusion coefficient, } \\
D\left(\times 10^{-9} \mathrm{~m}^{2} / \mathrm{s}\right)\end{array}$ & $\begin{array}{c}\text { Henry's coeffi- } \\
\text { cient, } k_{X}(\mathrm{GPa})\end{array}$ \\
\hline 0 & 0.87 & 4.38 \\
10 & 1.24 & 5.56 \\
20 & 1.67 & 6.73 \\
30 & 2.17 & 7.81 \\
40 & 2.74 & 8.82 \\
\hline
\end{tabular}

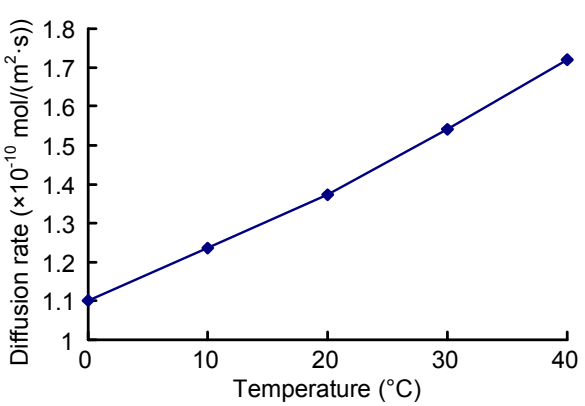

Fig. 4 Relationship between temperature and diffusion rate $F$ of air in water 
Since the molar volume $V_{\mathrm{m}}$ is around $0.15 \mathrm{~m}^{3} / \mathrm{mol}$, the accumulated air column increase at $40^{\circ} \mathrm{C}$ is therefore lower than $0.01 \mathrm{~mm}$ per day.

Based on the above discussion, it can be concluded that the air accumulation at the top of the siphon hose from air dissolution and diffusion is limited. Therefore, air diffusion at the top of the siphon hose will not result in a break in the siphon system due to stoppage of flow.

\subsection{Air release due to temperature variations}

Since air solubility decreases with temperature increase, a temperature increase will lead to a release of air, while a temperature decrease will result in air re-dissolution. In reality, the released air will accumulate at the top of the siphon hose when the temperature increases. However, if the temperature falls, air diffusion from top to bottom will seldom happen due to the concentration gradient, and so air can only be supplied from the outside. Thus, air release induced by temperature increase will always result in air accumulation. Next, an estimation of daily air accumulation as well as its effect on pressure is discussed.

The amount of air released from an infinitesimal $\mathrm{d} x$ can be expressed as

$$
\begin{aligned}
\mathrm{d} n_{B} & =\left(\frac{P_{0}-\rho g x}{k_{0}}-\frac{P_{0}-\rho g x}{k_{1}}\right) \frac{M_{B}}{M_{A}} \cdot \frac{\rho A}{M_{A}} \mathrm{~d} x \\
& =\frac{\left(k_{1}-k_{0}\right)\left(P_{0}-\rho g x\right) \rho A M_{B}}{k_{1} k_{0} M_{A}^{2}} \mathrm{~d} x,
\end{aligned}
$$

where $k_{0}$ and $k_{1}$ are the Henry's coefficients of air in water at temperatures $T_{0}$ and $T_{1}$, respectively. Air released from an air column with length $l$ can then be obtained by integrating Eq. (12) as

$$
\begin{aligned}
n_{B} & =\int_{0}^{l} \frac{\left(k_{1}-k_{0}\right)\left(P_{0}-\rho g x\right) \rho A}{k_{1} k_{0} M_{A}} \mathrm{~d} x \\
& =\frac{\left(k_{1}-k_{0}\right) \rho A M_{B}}{k_{1} k_{0} M_{A}^{2}}\left(P_{0} l-\frac{1}{2} \rho g l^{2}\right) .
\end{aligned}
$$

In this study, a general temperature ranging from $0{ }^{\circ} \mathrm{C}$ to $40^{\circ} \mathrm{C}$, for which Henry's coefficient $k$ ranges from $4.38 \mathrm{GPa}$ to $8.82 \mathrm{GPa}$, is investigated. Substituting these values into Eq. (13), the amount of air release due to a temperature variation from $0{ }^{\circ} \mathrm{C}$ to $40{ }^{\circ} \mathrm{C}$ is found to be $n_{B} \approx 5 \times 10^{-5} \mathrm{~mol}$.

Substituting the molar volume $V_{\mathrm{m}} \approx 0.15 \mathrm{~m}^{3} / \mathrm{mol}$ and assuming the diameter of the siphon hose is the same as for those discussed in Section 3.3, the temperature rise from $0{ }^{\circ} \mathrm{C}$ to $40{ }^{\circ} \mathrm{C}$ will result in an air column due to air release of a total length of $0.55 \mathrm{~m}$. Thus, air release from temperature rise plays an important role in air accumulation. However, the subsequent air supplement after air release is closely related to air diffusion after air re-dissolution at the top of the siphon hose. Fig. 5 shows the three steps of the air movement process due to temperature variation. Fig. 5 is the schematic diagram of a vertical siphon hose filled with static water. The bottom of the hose is under a standard atmosphere, and the top of it is at a vacuum. As a result, the solubility as well as the pressure of the air decreases linearly with the elevation of the hose. Assuming air is to be saturated at each elevation right after the siphon flow stops, the three steps of air release and the re-dissolution process are shown in Figs. 5a-5c. The horizontal lines represent the concentration of the dissolved air. Step 1 shows the dissolved air to be trapezoidally distributed under $0{ }^{\circ} \mathrm{C}$ (Fig. 5a); step 2 shows the dissolved air distribution when the temperature rises to $40{ }^{\circ} \mathrm{C}$ (Fig. 5b). As shown in Fig. 5b, a temperature increase leads to a decrease in air solubility, so the excess air is released and moves to the top of the siphon hose. Step 3 shows the re-dissolution and diffusion of air when temperature decreases back to $0^{\circ} \mathrm{C}$ (Fig. 5c), in which $H$ denotes the action length as shown in Eq. (16).

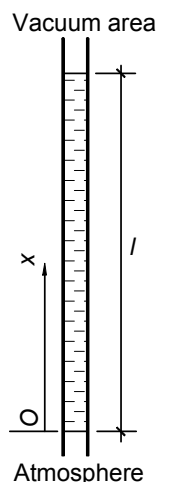

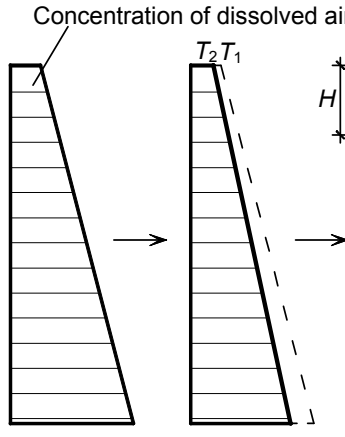

(a) (b)

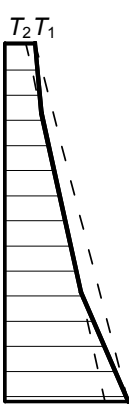

(c)
Fig. 5 Schematic diagram of air dissolution variation with changing temperature

(a) Step 1: saturated air solubility at $T_{1}$; (b) Step 2: temperature rises to $T_{2}$; (c) Step 3: cool-down to $T_{1}$ again 
Unlike air release, the dissolving process is closely related to air diffusion. According to the results discussed in Section 3.3, the diffusion rate of air in water is very slow at a certain temperature. For the case of a siphon hose with a length of $10 \mathrm{~m}$ or longer, the effective length of the dissolution and diffusion from such a long siphon hose is also very limited. In this study, the action length $H$ is defined as the influence part of the diffusion as shown in Fig. 6. For the area located below this part, the diffusion rate will be negligible compared with the diffusion rate due to the concentration difference discussed in Section 3.3. Take the case of a temperature decrease from $40{ }^{\circ} \mathrm{C}$ to $0{ }^{\circ} \mathrm{C}$ for example, the concentration of dissolved air at $1-1$ section is the solubility $C_{1}$ at $0{ }^{\circ} \mathrm{C}$, while that at 2-2 section is the solubility $C_{2}$ at $40{ }^{\circ} \mathrm{C}$. According to the principle of air permeation through solid flat wall (Gao and Cui, 1983), the variation of air solubility among the action length $H$ can be written as

$$
\begin{aligned}
C= & C_{2}+\left(C_{1}-C_{2}\right) \\
& \cdot\left[1-\frac{x}{H}-\frac{2}{\pi} \sum_{n=1}^{\infty} \frac{1}{n} \exp \left(-\frac{n^{2} \pi^{2} D}{H^{2}} t\right) \sin \left(\frac{n \pi}{H} x\right)\right],
\end{aligned}
$$

where $n$ comes from the Fourier series expansion. When the duration time $t$ is long enough, the effect of the exponential term in Eq. (14) can be neglected. As a result, the diffusion rate $F$ at $x=H$ can be calculated as

$$
F=-D \frac{\partial C}{\partial x}=\frac{D\left(C_{1}-C_{2}\right)}{H} .
$$

Under standard atmospheric pressure, the solubilities of air in water at $0{ }^{\circ} \mathrm{C}$ and $40{ }^{\circ} \mathrm{C}$ are $C_{1}=37.55 \mathrm{mg} / \mathrm{L}$ and $C_{2}=16.65 \mathrm{mg} / \mathrm{L}$, respectively. Taking $1 \%$ of the diffusion rate induced by the concentration gradient as discussed in Section 3.3 as the negligible rate $F_{n}$, and substituting the most conservative diffusion coefficient $D=2.74 \times 10^{-9} \mathrm{~m}^{2} / \mathrm{s}$ at $40^{\circ} \mathrm{C}$, the action length $H$ can then be obtained by

$$
H=\frac{D\left(C_{1}-C_{2}\right)}{F_{n}} \approx 1.1 \mathrm{~m} .
$$

Therefore, the effective length of air redissolution induced by a temperature decrease will not exceed $1.1 \mathrm{~m}$. As shown in Fig. 5c (step 3), the air solubility at the top of the siphon hose is relatively small due to the relative low pressure there. As a result, the action length $H$ induced by this effect is shorter than that induced at standard atmospheric pressure. Similarly, the temperature variation induced in the action length $H$ at the bottom of the siphon hose under standard atmospheric pressure is also shorter than that induced by the temperature changing from $40{ }^{\circ} \mathrm{C}$ to $0{ }^{\circ} \mathrm{C}$. As for $10 \mathrm{~m}$-long siphon hoses, several meters along the central part of the siphon hoses are rarely affected by air re-dissolution. Therefore, the air supplement in long siphon hoses due to temperature variation is very small. As a result, the amount of dissolved air in the central long water column remains nearly the same as that dissolved at the highest temperature in the year.

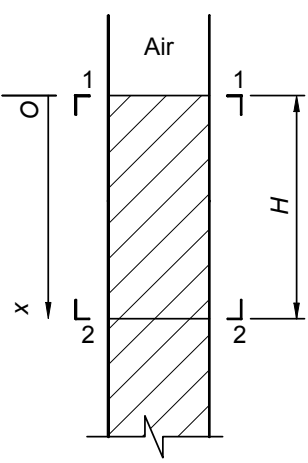

Fig. 6 Simplified physical model diagram

Based on the above analysis, it can be concluded that air release due to temperature increase can be treated as a one-time occurrence. Assuming the temperature at a certain area increases from $0{ }^{\circ} \mathrm{C}$ to $40^{\circ} \mathrm{C}$ in one year, a length of $0.55 \mathrm{~m}$ accumulated air column will be released due to the temperature increase. Such accumulated air column of course should be treated as air released from the original air in the siphon hoses. Therefore, in practical application, keeping a high flow velocity and a small temperature rise are effective ways to avoid the siphon flow stopping.

Taking both the original air release discussed in Section 3.2 and the temperature increase-induced one time air release discussed in Section 3.4 into consideration, at least $2.05 \mathrm{~m}$ space for underground water rise should be left, or the outlet should be kept just 
$4.1 \mathrm{~m}$ lower than the inlet to guarantee that the released air will be gathered in the descending hoses.

\section{Conclusions}

The accumulation of air due to air dissolution and diffusion at the top of a long-term-high-lift motionless siphon hose has been studied. Effects of unavoidable factors on air accumulation in dry seasons have been investigated. The following conclusions can be made from the experimental results and theoretical analyses:

1. Pressure decrease in high-lift siphon hoses will cause supersaturated air release and induce a maximum $1.5 \mathrm{~m}$ long air column at the top of the siphon hose.

2. Temperature increase can induce a maximum $0.55 \mathrm{~m}$ long air column. On the other hand, air redissolution and supplement from temperature decrease can only affect a less than $1.1 \mathrm{~m}$ length of water column, which is negligible in a high-lift siphon.

3. Air diffusion from water will lead to a less than $0.01 \mathrm{~mm}$ increment of air column at the top per day, which is considered to be negligible compared with that induced by air release due to pressure and temperature variations.

Results in this study indicate that high-lift siphon drainage can also be effectively used in districts where it seldom rains. In siphon drainage design, at least $2.05 \mathrm{~m}$ long space to the safety level should be left for underground water rise, or just keeping the outlet $4.1 \mathrm{~m}$ lower than the inlet can guarantee that the released air will be gathered in the descending hoses.

\section{Acknowledgement}

The authors would like to thank Dr. Jia-yi SHEN, Dr. Li-feng FAN, and Ms. Yan-mei DENG from Ocean College, Zhejiang University, China, and Ms. Yi-qing XU from Zhejiang Shuren University, China for reviewing and polishing this paper.

\section{References}

Benson, B.B., Krause, D.Jr., 1984. The concentration and isotopic fractionation of oxygen dissolved in freshwater and seawater in equilibrium with the atmosphere. Limnology and Oceanography, 29(3):620-632. [doi:10.4319/ lo.1984.29.3.0620]

Cai, Y.L., Sun, H.Y., Shang, Y.Q., et al., 2014. An investigation of flow characteristics in slope siphon drains. Journal of Zhejiang University-SCIENCE A (Applied Physics \& Engineering), 15(1):22-30. [doi:10.1631/jzus.A1300178]
Campbell, D.P., 2014. Novel modulated flow, self configuring, siphonic roof drainage system. Building Services Engineering Research and Technology, 35(4):349-361. [doi:10.1177/0143624413497482]

Chen, Y.Y., Tang, H.M., Zhou, Z.M., et al., 2006. Optimization of port bank slope drainage technique in Three Gorges area. Port \& Waterway Engineering, 5:50-54 (in Chinese).

Cussler, E.L., 1984. Diffusion, Mass Transfer in Fluid Systems. Cambridge University Press, Cambridge, UK.

Fekete, S., Horváth, K., Guillarme, D., 2013. Influence of pressure and temperature on molar volume and retention properties of peptides in ultra-high pressure liquid chromatography. Journal of Chromatography A, 1311:65-71. [doi:10.1016/j.chroma.2013.08.045]

Frank, H.S., Evans, M.W., 1945. Free volume and entropy in condensed systems III. Entropy in binary liquid mixtures; partial molal entropy in dilute solutions; structure and thermodynamics in aqueous electrolytes. The Journal of Chemical Physics, 13(11):507-532. [doi:10.1063/1. 1723985]

Gao, B.H., Cui, S.Y., 1983. Vacuum Physics. Science Press, Beijing, China, p.570-575 (in Chinese).

Gress, J.C., 1988. Device for draining soils in depth. US Patent 4717284 .

Gress, J.C., 1991. Device for regulating the flow in a drainage siphon tube. US Patent 5035535.

Gress, J.C., 2008. New formulae to assess soil permeability through laboratory identification and flow coming out of vertical drains. Proceedings of the 10th International Symposium on Landslides and Engineered Slopes, Xi'an, China, p.361-364. [doi:10.1201/9780203885284-c34]

Hager, W.H., 2010. Pipe culverts-throttling pipes-inverted siphons. In: Wastewater Hydraulics. Springer Berlin Heidelberg, p.263-287. [doi:10.1007/978-3-642-11383-3]

Hughes, S., Gurung, S., 2014. Exploring the boundary between a siphon and barometer in a hypobaric chamber. Scientific Reports, 4:4741. [doi:10.1038/srep04741]

Jacobson, T., 1995. Thermodynamics of spacetime: the Einstein equation of state. Physical Review Letters, 75(7): 1260. [doi:10.1103/PhysRevLett.75.1260]

Lu, L.G., Gao, D.Y., Zhu, J., 2005. Optimum hydraulic design of siphon outlet in large pumping stations. Transactions of the Chinese Society of Agricultural Machinery, 36(4): 60-68 (in Chinese).

Mrvik, O., Bomont, S., 2012. Experience with Treatment of Road Structure Landslides by Innovative Methods of Deep Drainage. In: Mambretti, S. (Ed.), Landslides. WIT Press, UK, p.79-90.

Radke, C.J., Prausnitz, J.M., 1972. Thermodynamics of multisolute adsorption from dilute liquid solutions. AIChE Journal, 18(4):761-768. [doi:10.1002/aic.690180417]

Ramette, J.J., Ramette, R.W., 2011. Siphonic concepts examined: a carbon dioxide gas siphon and siphons in vacuum. Physics Education, 46(4):412. [doi:10.1088/0031-9120/ 46/4/006]

Sanjari, E.A., 2013. New simple method for accurate calculation of saturated vapor pressure. Thermochimica Acta, 560:12-16. [doi:10.1016/j.tca.2013.03.002]

Sun, H.Y., Xiong, X.L., Shang, Y.Q., et al., 2014. Experimental 
study on the process of bubble accumulation in slope siphon drainage. Journal of Jilin University (Earth Science Edition), 44(1):278-284 (in Chinese).

Xu, H., Liu, Q.Z., Hu, Y.D., et al., 2009. Molecular dynamic simulation of diffusion coefficient of gas in water. Computer and Applied Chemistry, 26(2):153-156 (in Chinese).

Yang, Y.Y., Yao, A.J., Zhang, Z.M., et al., 2009. Experimental study of controlling groundwater technology for bank slope. Rock and Soil Mechanics, 30(8):2281-2285 (in Chinese).

Zhang, Y.F., Zhang, Y.J., 1999. Research on siphon drainage application technology. China Railway Science, 20(3): 52-60 (in Chinese).

\section{中文概要}

题 目: 空气溶入与扩散对高扬程虹吸管内空气积累影响

目 的：探索长时间停流情况下高扬程虹吸管中空气累积 现象的发生发展及其对虹吸持续工作的危害, 并 给出应对该现象的工程预防措施。
创新点: 利用物理模型实验, 结合理论解析推导, 得到高 扬程虹吸管内空气累积的原因及关键影响因素, 突破高扬程虹吸排水在少雨地区的使用局限, 给 出其长期适用的工程设计条件, 对其在实际边坡 工程中的推广应用提供理论技术指导。

方 法: 通过物理模型试验, 揭示长期停流虹吸管内出现 空气累积的必然性; 利用理论公式推导, 对不同 因素的影响结果进行对比分析, 得出影响空气累 积的主要因素。

结 论: 1. 溶于水的空气因压力降低而析出、管端空气溶 入扩散到虹吸管顶部及温度变化引起空气析出 等现象是无法避免的; 其中, 原有空气的析出及 温度变化引起的空气累积是主要因素; 2. 边坡虹 吸排水设计时进水端口距控制水位至少应预留 $2.05 \mathrm{~m}$ 的地下水位上升余量, 或者保持出水口的 高程比进水口高程低 $4.1 \mathrm{~m}$ 来保证析出空气段处 于下水管中。

关键词: 边坡; 虹吸排水; 旱季停流; 空气累积; 气体扩 散; 温度 